\title{
Review of Accident Reporting and Prevention System
}

\author{
Shankar Pawar ${ }^{1}$, Ajay Barkade ${ }^{2}$, Samruddhi Kulkarni ${ }^{3}$, Er. Chandan Prasad ${ }^{4}$ \\ B. Tech Scholar, CTIS, School of Information \& Technology, Pune, India ${ }^{1}$ \\ BCA Scholar, MACT, School of Information \& Technology, Pune, India ${ }^{2,3}$ \\ Assistant Professor, IT, Ajeenkya DY Patil University, Pune, India ${ }^{4}$
}

\begin{abstract}
Speeding and drunken drive are the basic reasons for vehicle accident. Many lives could have been saved if emergency service could get accident information and touch in time and if drunken drivers are prevented from driving. Vehicle accidents are one of the most leading causes of casualty. The time between an accident occurrence and the emergency medical personnel are dispatched to the accident location is the important factor in the survival rates after an accident. By eliminating that time between an accident occurrence and the first responders are dispatched to the scene decreases mortality rates so that we can save lives. In this paper we are focusing about the all the existing system or analogies for accident reporting and prevention to compile a new system which is enhanced and concise of existing attributes. Above all we are thinking about the system which reduce time of action such as intimation to police, intimation to traffic police, intimation to family, intimation to hospital and many more aspect.
\end{abstract}

Keywords: Vibration detection, GPS, GSM, MEMS, ARM, Emergency call system, Alcohol gas sensor, Raspberry Pi, Ultrasonic Sensor, SMS, Microcontroller 8051, Location Tracking.

\section{INTRODUCTION}

Road Transport leads the transportation mediums in India. collision [1].This system had a major disadvantage But the road conditions in the country is pitiable. Traffic because the details are interchanged via RFID between the Collisions, Motor Vehicle Collisions (MVC) to be vehicles only, the storage of vehicle details in database of specific, occur when motor vehicles accidentally collides Cops server or any other external unit wasn't incorporated. with another vehicle, pedestrian, animal, road debris, or The methodology [2] elaborate the usage of Global other stationary obstruction, such as a tree or pole.

Positioning System and Zigbee to show the accident In the recent periods, the population and technological location to the given contact person number as an act of growth has exceeded to the limits of extremes. As the providing information about the accident. This system populace is increasing rapidly it discursively implies high approach wasn't real since it lacks active tracking of number of vehicles. Loopholes in traffic management, vehicle and storage of path taken by vehicle etc., which is ignorance to follow proper traffic guidelines and the basic need to catch the hit and run driver.

sometimes twist of fate contributed together gives rise to a higher figure of Motor Vehicle Collisions. The result of these three is devastating for some. Some costing economical losses, some medically and for some unfaithful life itself. Statically, Road collisions are the second highest death reason for the people between ages 15 to 50. The Paper hence discusses a severe subject, loopholes in it and a proposed system to overcome the hurdles. The paper also reviews thoroughly about the existing systems, their features and limitations.

\section{LITERATURE SURVEY}

There are numerous struggles made in order to sidestep accidents i.e., there has been several accident prevention system and mobile applications approaches are available to trail the lost vehicle. One of the tactics to classify the vehicles intricate in collision, permitted to exchange particulars between the two vehicles at the time of

The system given in this paper [3] includes PIC microcontroller along with GPS- GSM module to offer the alert message with location to the Control Section, from which a message is send to the close ambulance to make available medical support. This system [3] overcame the boundaries of [1] and [2]. But it has limitation due to which delay in the time of implementation, message and reply because PIC does not provide finest compiler and application support and also has slow speed of operation taking 4 clocks /instruction cycle. Since most of the traffic accidents are due to the human faults, [4] provides alogical approach to study the behaviour of the driver under all the potential threats. Driver behaviour sketching system [5] uses a fussy logic to compute the score for dissimilar drivers by providing route topology, weatherconditions, and detects the uncertain driving events and also the probable threats. In order to detect the collision in road scenes, an algorithm was developed to calculate crash 


\section{ISO 3297:2007 Certified}

Vol. 5, Issue 3, March 2017 possibilities [6]. This is effective in terms of collision warning,crash evading and also mitigation. But it doesn't provide the support during its aftermath of accident. The system [7] includes microcontroller, GPS and GSM to send message about the vehicle crash to the given numbers likeambulance, police station, etc.

This system [8] which would help to locate vehicle that initiated hit and run accident and also provides emergency medical support in order to mitigate the fatalities in road accidents. Thus the driver who caused accident leading to injury or death and left the scene of accident would be subjected to serious criminal charges. The continuous and intervallic monitoring of the vehicles will reduce the number of accidents in the roads.

This system [9] has accident avoidance technology which would decrease the accident of the vehicle in crowd areas. This vehicle accident avoidance, revealing and aware systems provide emergency response with crucial information at the earliest possible time. Dropping the time between when an accident takes place and when it is detected can reduce mortality rates.

This system [10] designed as ashrewd anti-theft system that uses GPS and GSM system to prevent theft and to decide the exact location of vehicle. The system contains GPS module, GSM modem, Infrared sensors, DTMF decoder IC MT8870DE, 8051 microcontroller, relay switch, vibration sensor, paint spray and high voltage mesh. GSM system is also installed in the vehicle for sending the info to the owner of the vehicle because GPS system can only receive the vehicle position information from satellites. This system automatically sends the message for help to ones relatives. The defensive measures like engine ignition cutoff, fuel supply cutoff, electric shock system (installed on steering wheel) and paint spray system are installed in the vehicle which is controlled using user or owner GSM mobile. The owner can lock or unlock his/her vehicle with the help of SMS. This system is for low range vehicles to provide them extreme security. This paper [11]gives the shortest path by controlling traffic signals in favour of ambulance. By this system the time interval is abridged by applying the RF technologies that pedals the traffic signals. The precedence ofservice to the ambulance follows the queuing methodologiesthrough server communication. This ensures the reduced time delay between the accident location and hospital.

This paper gives the framework which is positioned in moving vehicle to detect accident and report to In Case of Emergency (ICE). The initial responder is getting notice through GSM and in addition to that the vehicle accident zone longitude and latitude information is obtained through GPS and GPRS.The given system can save life as the ICE team reaches the spot on time, take care of the victim and give medical treatment on time. The black box will accounts the voice of victim after the accident occurs which will be used for further analysis.

\section{III.CONCLUSION}

An accident is an unforeseen and unintentional event. In today's world road accidents viewpoint among the leading cause of human death,Road safety for driver is an essential requirement of society, As the Number of vehicles increase day by day, Collision of vehicle also increases extensively, in this situation this paper fulfils the purpose of saving lives first by analysis the loophole in the existing systems. A system is needed which the system which reduce time of action such as intimation to police, intimation to traffic police, intimation to family, intimation to hospital and many more aspect.

\section{REFERENCES}

1] NayanJeevagan, PallaviSantosh, RishabhBerlia, and Shubham Kandoi, "RFID Based Vehicle Identification During Collisions", Global Humanitarian Technology Conference (GHTC), IEEE, pp. 716-720, Oct. 2014

[2] N.Suganya andE.Vinothini, "Accident Alert and Event Localization", International Journal of Engineering and Innovative Technology (IJEIT) Vol. 3, Issue 8, pp. 53-54, Feb 2014

[3] S.Iyyappan and V.Nandagonal, "Automatic Accident Detection And Ambulance Rescue With Intelligent Traffic Light System", InternationalJournal of Advanced Research in Electrical, Electronics and Instrumentation Engineering, Vol. 2, Issue 4,pp. 1319-1325, April 2013

4] Lucas Malta, ChiyomiMiyajima, and Kazuya Takeda, "A Study of Driver BehaviourUnder Potential Threats in Vehicle Traffic", IEEETransactions on Intelligent Transportation Systems, Vol. 10, No.2, pp. 201-210, June 2009.

5] German Castignani, Thierry Derrmann, Raphael Frank and Thomas Engel, "Driver Behaviour Profiling Using Smartphones: A LowCostPlatform for Driver Monitoring", IEEE Intelligent Transportation Systems magazine, pp. 91-102,2015.

[6] Taewung Kim and Hyun-Yong Jeong, "A Novel Algorithm for Crash Detection Under General Road Scenes Using Crash Probabilities and an Interactive Multiple Model Particle Filter", IEEE Transactionson Intelligent Transportation Systems, Vol. 15, No. 6, pp.2480-2490, Dec. 2014.

[7] AboliRavindraWakure and ApurvaRajendraPatkar, "Vehicle Accident Detection and Reporting System Using GPS and GSM", International Journal of Engineering Research and Development,Vol.10, Issue 4, pp.25-28,April 2014.

8] R.Aishvarya, S.Poornima, K.Pradeepa, T.Subashini, K.P.Lavanya," Automatic and Effective Tracking of Hit \& Run Misbehavior Driver with Emergency Ambulance Support",IJAREEIE, Vol. 5, Issue 3, March 2016.

[9] Monika S. Tayde, Aruna P. Phatale," Study on Intelligent Automatic Vehicle Accident Prevention a nd Detection System", IJAREEIE, Vol. 5, Issue 5, May 2016.

[10] G. Divya, A. Sabitha, D. Sai Sudha, K. Spandana, N. Swapna, J. Hepsiba, "Advanced Vehicle Security System with Theft Control and Accident Notification using GSM and GPS Module", IJIREEICE, Vol. 4, Issue 3, March 2016.

[11] Kavya K, Dr. Geetha C R, "Accident Detection and Ambulance Rescue using Raspberry Pi”, IJET, Vol 2 Issue 3, May - June 2016.

[12] Dr.J.L.Mazher Iqbal , S.Heena Kousar , "Automatic Vehicle Accident Detection and Reporting With Black Box", IJAER, Vol. 10, December 2015 